\title{
Why trivialising people's culture can be catastrophic for the effective communication of extreme weather warnings: lessons from the Delta State of Nigeria
}

\author{
Eromose E. Ebhuoma \\ Postdoctoral research fellow, University of Johannesburg \\ Rm G03, Postgraduate Center, 5 Kingsway Avenue, Rossmore, Johannesburg, South Africa. 2092
}

\begin{abstract}
Early weather warnings can save lives and minimise the loss of assets. The most accurate forecast, however, is useless if it fails to reach those anticipated to be affected by a predicted adverse weather condition, as this will impede their ability to act pro-actively. The 2012 flood disaster in Nigeria which had devastating consequences for 30 states in the country, for example, was forecasted a few months ahead by the Nigerian Meteorological Agency. However, data obtained from some rural communities in the Delta state that suffered severe implications courtesy of the flood revealed that the warning did not get to most households. This was largely due to the relevant authority's failure to utilise the communication techniques and strategies employed by rural households when disseminating vital information to members of their respective communities. This paper argues that it is crucial to reconsider contemporary systems of communications and adopt more pro-poor communication techniques that are underpinned by cultures and traditions. Otherwise, future early warning communications to rural households in the Delta state will likely fail to trigger the intended reaction.
\end{abstract}

Keywords - Extreme weather warnings, risk communication, rural households, Nigeria

SUGGESTED CITATION: Ebhuoma, E. E. (2018). Why trivialising people's culture can be catastrophic for the effective communication of extreme weather warnings: lessons from the Delta State of Nigeria. Proceedings of the International Crisis and Risk Communication Conference (pp. 38-41). Orlando, FL, USA. Nicholson School of Communication. https://doi.org/10.30658/icrcc.2018.11

\section{INTRODUCTION}

Effective communication of extreme weather warnings is crucial because of its potential to save lives and drastically reduce loss of assets. From a developing world perspective, however, communicating weather warnings efficiently, especially to rural households, remains a huge challenge for risk communicators mainly because of their overwhelming reliance on the mass media [1]. This is arguably because the mass media is extremely cost-effective [2]. However, factors such as entrenched poverty, which can make gadget such as television (TV) set a luxury for some rural households, and lack of constant power supply can suffocate the effectiveness of TV and radio as useful communication channels [3].

In the 1991 cyclone in Bangladesh, for example, Chowdhury et al. [4] argued that the use of radio and TV to disseminate the anticipated cyclone only proved effective in areas that were in proximity to major cities than those farther from the cities. It is within this context that Moser and Dilling [5] asserts that, an adequate understanding of the ways in which the target audience prefers to receive messages and the way information is communicated among community members are pre-requisites for communicating extreme weather warnings effectively. Simply put, a one-size-fits-all approach will not suffice for different vulnerable households.

In light of the above, it can be argued that the relevant authorities in Nigeria failed to realise that a one-size-fits-all approach might be grossly inadequate before communicating the 2012 flood forecasts to members of the public. The forecast, which was publicised through the mass media, pinpointed the Delta state as a region to receive one of the highest amounts of rainfall [6]. Despite the warning, households residing in several rural communities along the coastal 
regions in the Delta state were caught off-guard [7].

Against this background, this paper seeks to illuminate the adverse implications of relying solely on the mass media, as a viable means of communicating extreme weather warnings to rural households in the Delta state. With climate projections indicating that extreme weather conditions will become the new normal for Nigeria from 2030, coupled with the Nigerian government's investment in meteorological services and technology, it is important to reconsider contemporary systems of communicating extreme weather warnings.

\section{METHODOLOGY}

This study was conducted in Olomoro, Igbide and Uzere communities, situated in Isoko South Local Government Area (ISLGA) in the Delta state (figure 1). Small-scale farming is the primary economic driver (over 90\%) of these predominantly rural communities, with the women heavily involved in the practice.

Focus group discussions (FGD) and semi-structured interviews were the main methodological tools used to collect primary data. The study comprised 35 FGD's and four one-to-one, semi-structured interviews conducted between June and October 2015. Each FGD was made up of three and 12 participants between the ages of 20 and 85 . Of the 35 focus groups, 24 were made up of female participants, five were made up of male participants, while 6 comprised both male and female participants. The primary reason for having more female FGDs is because feminisation is the primary driver of subsistence farming in rural developing countries. Also, a semi-structured interview was conducted with a senior official, in his 30's, of the Nigerian Red Cross Society (NRCS) in the Delta state, who was actively involved in the search and rescue operation during and in the aftermath of the 2012 flood.

Participants in each community were identified using purposive sampling technique based on age, gender, those who have been farming in the study area for over ten years on the low-lying farmlands, and those whose household assets and livelihoods were adversely affected by the 2012 flood disaster. The qualitative data were analysed using the thematic content analysis technique.

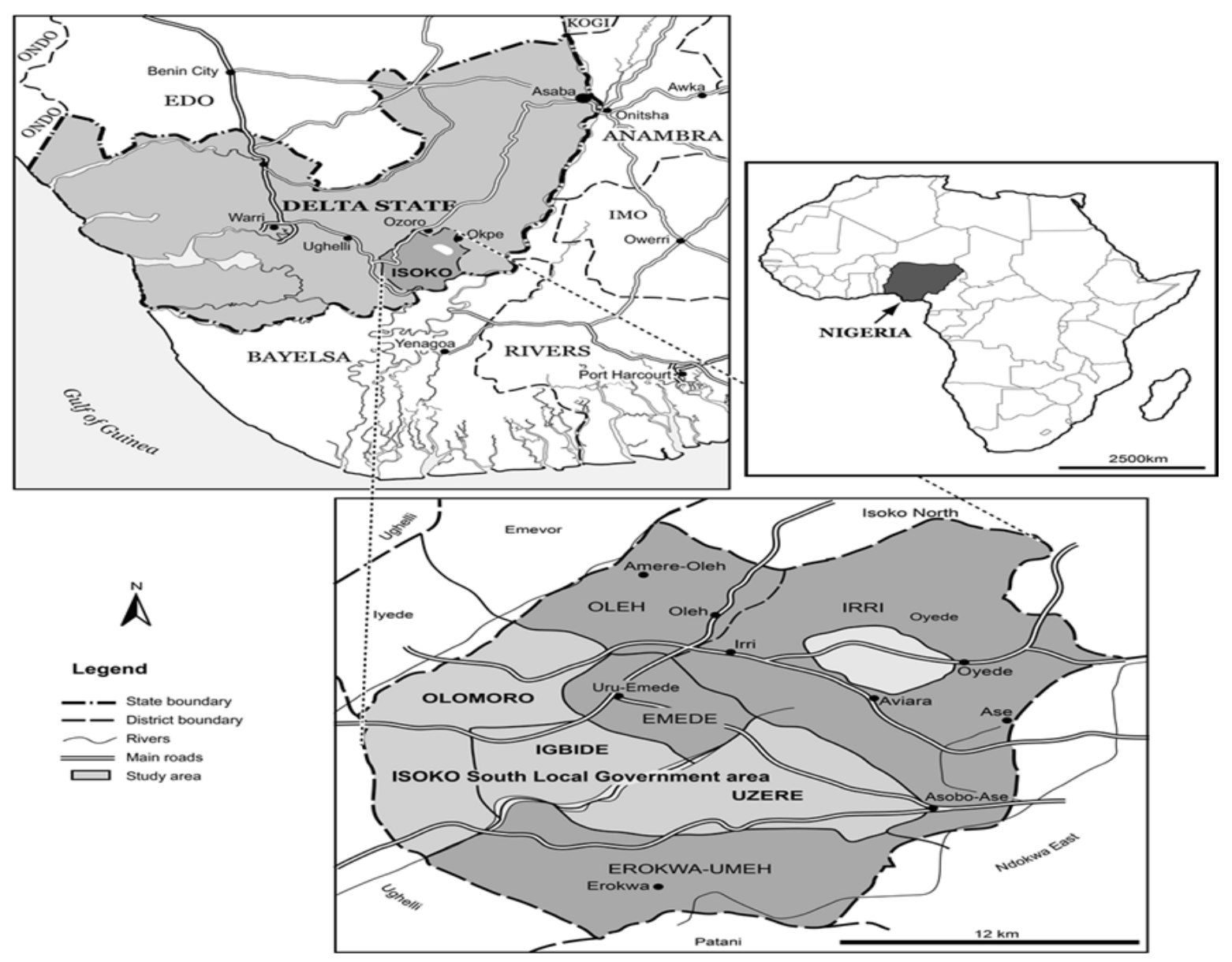

Figure 1: Map of the study areas. 


\section{RESULTS}

\section{CHANNELS USED TO CONVEY THE 2012 FLOOD WARNING}

Between July and October 2012, Nigeria experienced its worst ever flood disaster in its entire history. Approximately 7 million people were displaced nationwide. Fieldwork revealed that Igbide, Uzere and Olomoro communities were heavily affected to the point that some individuals, who refused to evacuate their homes for fear of hoodlums stealing their household assets, relied on canoes to move from one location to another within their respective communities.

When participants were asked if they received the forecast, all but one stated that they never received any forecast. The participant who argued that she heard of the flood warning, a lady from Igbide in her late 40's, echoed that it was broadcasted through the radio. Her opinion was corroborated by the senior official of the NRCS in the Delta state. He argued that the flood was warning was disseminated through the use of flyers, as well as radio and television jingles. However, a female participant from Igbide who took part in the FGD where the lady affirmed that the forecast was aired on the radio, in her 50's, expressed disdain at the preferred medium of communication. She lamented:

We leave our homes for the farm first thing in the morning (except Sundays and market days, which occurs every four days). By the time we get back home we are completely exhausted. The only thing on our mind is to get reenergised for the next day's activities. What time do we have to listen to the radio?

It can also be argued that the lack of constant power supply in Nigeria severely hampered the use of the mass media. During a FGD in Olomoro, for example, the participants stated that they have not had electricity for the past two weeks, which is almost symptomatic of the power situation in most part of the country.

\section{EFFECTIVE MEDIUMS OF COMMUNICATING EARLY WEATHER WARNINGS}

The participants in the aforementioned communities argued that the most effective ways of communicating important messages in their communities are mainly through town-hall meetings and the use of town criers. In this regard, a participant from Uzere, in his early 30's, commented:

When you call for a town-hall meeting, not everybody will be able to make it. But there is always the tendency for a household member or a neighbour to be present who will help divulge the information to the absentees.

The use of town criers, on the other hand, entails an individual walking through the community with a gong and an iron rod that produces a resonant, vibrating sound when struck to get the attention of community members after which the necessary information is aired vocally. The participants pointed out that this medium has been highly effective in the past and it's still heavily relied upon in keeping members abreast with events and happenings within the community. Their views were buttressed by the red-cross official who emphasised that the most efficient ways to enlighten rural households are through frequent town-hall meetings, use of town criers and door to door enlightenment.

\section{DISCUSSION}

Communicating extreme weather warnings in order to trigger pro-active measures by those expected to be susceptible to the anticipated extreme weather conditions are no small feat. From the result, it is evident that the use of the mass media alone to disseminate the 2012 flood warning to households in Igbide, Uzere and Olomoro communities proved grossly ineffective. This observation is in stark contrast with several findings which suggest that the use of radio, for example, is an effective tool for communicating extreme weather warnings to poor rural households in developing countries [8]. Writing from an Indian context, Bisht and Ahluwalia [8], contend that community radio transcends barriers such as illiteracy, accessibility, affordability and local relevance, known to impede the flourishing of other channels of communication in rural spaces. In the aforementioned communities, however, there are no community radio stations. Even if they were community radio stations, its effectiveness as the only medium of communicating extreme weather warnings, I argue, cannot be totally guaranteed.

This is based on two premises: first, the lack of constant electricity supply in Nigeria will hamper the effectiveness of community radio [see 1]. This point is reinforced by the Economist [9] who underlined Nigeria as 'one of the world's darkest nations'. Second, while farming remains the primary source of livelihood for most poor rural households in the Delta state, they are deeply entrenched in a complex web of non-farming activities in order to obtain the livelihood they aggressively pursue [7]. Thus, they barely have 'any ounce of energy' left in them to watch TV or listen to the radio when they get back home, as the only thing on their mind is to get a befitting rest.

In this light, therefore, it is crucial for risk communicators to identify and utilise more pro-poor communication channels that rural households rely upon to disseminate vital pieces of information that are underpinned by customs and traditions. Nonetheless, a plausible explanation that might have persuaded NIMET to rely extensively on the mass media is due to lack of financial capital, which stifles the department's effectiveness to execute its mandated tasks and objectives [10]. 


\section{CONCLUSION}

Early weather warnings have the potential to save lives and minimise loss of assets only when the risks are adequately communicated, through the right channels, to those likely to be affected by the anticipated early warnings. As revealed in this paper, the 2012 flood warning failed to reach those residing in the study areas because NIMET ignored the various ways these rural communities publicise vital pieces of information within their community. My message is not that the use of the mass media should be abolished in communicating extreme weather warnings to poor rural households in Nigeria or in rural sub-Saharan Africa, as it has proved overwhelmingly useful in some parts of the developing world [8]. Rather, if the goal of communicating extreme weather warnings is to trigger pro-active behaviour, it is critical for due attention to be paid to specific contexts and incorporate the local ways rural households publicise vital pieces of information.

\section{Author Biography}

Eromose E. Ebhuoma obtained his $\mathrm{PhD}$, in 2017, from the University of the Witwatersrand. He is currently a postdoctoral research fellow at the University of Johannesburg. Eromose2012@gmail.com; Eromosee@uj.ac.za.

\section{REFERENCES}

[1] Ajibade, I. and McBean, G. (2014). Climate extremes and housing rights: A political ecology of impacts, early warning and adaptation constraints in Lagos slum communities. Geoforum, 55, 76-86. https://doi.org/10.1016/j.geoforum.2014.05.005

[2] Harvatt, J., Petts, J. and Chilvers, J. (2011). Understanding householder responses to natural hazards: flooding and sea-level rise comparisons. Journal of Risk Research 14, 63-83. https://doi.org/10.1080/13669877.2010.503935

[3] Mushengyezi, A. (2003). Rethinking indigenous media: rituals, 'talking' drums and orality as forms of public communication in Uganda. Journal of African Cultural Studies 16, 107-117. https://doi.org/10.1080/136968103200169302

[4] Chowdhury, A.M.R., Bhuyia, A.U., Choudhury, A.Y. and Sen, R. (1993). The Bangladesh Cyclone of 1991: Why So Many People Died. Disasters 17, 291-304. https://doi.org/10.1111/j.1467-7717.1993.tb00503.x

[5] Moser, S.C. and Dilling, L. (2011). Communicating climate change: closing the science-action gap. The oxford handbook of climate change and society. Oxford University Press, Oxford 161-174.

[6] Vanguard (2012). 2012 year of flood fury: A disaster foretold, but ignored? Retrieved from http://www.vanguardngr.com/2012/10/2012-year-of-flood-fury-a-disaster-foretold-but-ignored/ (10.10.2016).

[7] Ebhuoma, E. and Simatele, D. (2017). Defying the odds: Climate variability, asset adaptation and food security nexus in the Delta State of Nigeria. International Journal of Disaster Risk Reduction 21, 231-242. https://doi.org/10.1016/j.ijdrr.2016.12.017

[8] Bisht, H. and Ahluwalia, N. (2015). Community radios and climate change communication: Mapping grassroots experiences of the 'Shubh Kal'Project in Bundelkhand, Central India. Retrieved from http://www.devalt.org/newsletter/sep13/of_4.htm (24.04.2017).

[9] The Economist (2016). Powerless: electricity in Nigeria. Retrieved from https:/www.economist.com/news/middle-eastand-africa/21693971-nigeria-has-about-much-electricity-edinburgh-problem-powerless (24.04.2017).

[10] Daily Trust (2012). Nigeria: Lack of Funds Hamper NIMET's Education of Farmers - Official. Daily Trust (Abuja). Retrieved from http://allafrica.com/stories/201208290796.html (25.04.17). 